\title{
Nematode beta diversity on the continental slope of New Zealand: spatial patterns and environmental drivers
}

\author{
Daniel Leduc ${ }^{1,2, *}$, Ashley A. Rowden ${ }^{2}$, David A. Bowden ${ }^{2}$, Scott D. Nodder ${ }^{2}$, \\ P. Keith Probert ${ }^{1}$, Conrad A. Pilditch ${ }^{3}$, Gerard C. A. Duineveld ${ }^{4}$, Rob Witbaard ${ }^{4}$ \\ ${ }^{1}$ Department of Marine Science, University of Otago, PO Box 56, Dunedin, New Zealand \\ ${ }^{2}$ National Institute of Water and Atmospheric Research (NIWA) Ltd, Private Bag 14-901, Kilbirnie, Wellington 6021, \\ New Zealand \\ ${ }^{3}$ Department of Biological Sciences, University of Waikato, Private Bag 3105, Hamilton, New Zealand \\ ${ }^{4}$ Royal Netherlands Institute for Sea Research (NIOZ), PO Box 57, 1790 AB Den Burg, Texel, The Netherlands
}

\begin{abstract}
The management of marine biodiversity relies on sound knowledge of beta (or turnover) and gamma (or regional) diversity patterns, but such knowledge is largely lacking for continental slope environments. Here, we used free-living nematodes to investigate spatial and environmental patterns of beta and gamma diversity on 2 major seabed features of the New Zealand continental slope, Chatham Rise and Challenger Plateau. Species gamma diversity on Chatham Rise was about twice that observed on Challenger Plateau, which likely reflected the greater number of sites sampled and greater range of environmental conditions encompassed by our sampling on the former. Mean Bray-Curtis dissimilarity in community structure/composition (i.e. beta diversity) between Chatham Rise and Challenger Plateau, though high $(>80 \%)$, was only marginally greater than within-region dissimilarity, and the beta diversity patterns we observed were mainly driven by factors acting at smaller (i.e. among-site) spatial scales. Sediment physicochemical characteristics (i.e. microhabitat heterogeneity) were the main environmental driver of nematode species and genus beta diversity, and explained about a fifth of the variability. Spatial structure explained a similar proportion of species beta diversity, which, because our sampling strategy was designed to maximise the range of environments sampled across the study areas, may suggest an influence of environment at scales beyond that of the individual cores. A similarity profile test (SIMPROF) identified 9 sample groups based on species data, suggesting a relatively high level of heterogeneity on the open slope of New Zealand.
\end{abstract}

KEY WORDS: Chatham Rise · Challenger Plateau $\cdot$ Community structure $\cdot$ Sediment characteristics Organic matter input $\cdot$ Habitat heterogeneity $\cdot$ Taxonomic resolution

\section{INTRODUCTION}

Describing and understanding beta diversity patterns (i.e. change in community composition/structure along spatial and environmental gradients; Anderson et al. 2011) is an important component of community ecology (e.g. Ellingsen \& Gray 2002, Thrush et al. 2010). Lack of independence between sites due to geographical proximity (i.e. spatial autocorrelation/structure), however, is thought to be common in natural communities and poses problems for the interpretation of ecological patterns (Legendre 1993). In particular, failure to take into account the spatial component of ecological variation may affect tests of statistical significance when investigating relationships between diversity and environmental para- 
meters (Legendre \& Troussellier 1988), but few beta diversity studies in the marine environment have considered the intrinsic spatial component of community composition (but see Merckx et al. 2009, Proches et al. 2010).

There has been increased interest in better quantifying spatial patterns of marine beta diversity in the last decade because of the pivotal role of beta diversity in relation to population connectivity and resilience (Thrush et al. 2009), environmental classification (Hooper et al. 2002) and conservation (Thrush et al. 2010). Defining community boundaries in the deep sea poses considerable challenges not only due to the difficulties in obtaining the required biological information, but also in relation to the interpretation of such data (Ricklefs 2008, Rex \& Etter 2010). Clustering techniques that use resemblance measures (e.g. dissimilarity among samples of species) have helped provide objective methods for the delimitation of 'natural' communities, but they are less useful (or even misleading) when there is a gradual change in community composition between sites (Clarke \& Warwick 2001), or impractical when they identify more communities than can be represented by a workable conservation/management scheme. Moreover, biogeographical subdivisions based on community composition patterns of different taxa are rarely consistent (e.g. Cartes et al. 2003). Thus, some degree of subjectivity is difficult to avoid when delimiting community boundaries for management purposes.

Our knowledge of the drivers of beta diversity in the marine environment, and in the deep sea in particular, is limited relative to terrestrial and freshwater ecosystems (Rex \& Etter 2010). The majority of deepsea studies of community composition have focused on depth-related patterns, with species turnover rates usually directly related to differences in water depth, and only weakly or not related at all to distance (Rex \& Etter 2010). The rate of species replacement for mega-, macro- and meiofauna is usually greater on the continental slope, particularly at upper to midbathyal depths, than in the abyss, i.e. $>4000 \mathrm{~m}$ see Rex \& Etter 2010 and references therein). This pattern probably reflects the relatively steep environmental gradients, complex topography and high environmental heterogeneity associated with bathyal zones (both vertically and horizontally) relative to deeper regions. Environmental factors such as organic matter input (Hecker 1990), input of terrestrial material (Galéron et al. 2009), currents (Blake \& Grassle 1994), macrohabitat heterogeneity (Gooday et al. 2010), temperature (Howell et al. 2002), oxygen con- centration (Levin et al. 2000) or a combination thereof are likely to be involved in determining beta diversity patterns in bathyal habitats. Thus, the continental slope is the ideal system for studying spatial patterns of deep-sea beta diversity and their potential environmental causes.

Nematodes are the most abundant (Giere 2009), and arguably the most diverse, animals in the deepsea benthos (Lambshead \& Boucher 2003). They also make a substantial contribution to deep-sea ecosystem functioning (e.g. Baguley et al. 2008). The majority of beta diversity studies in the deep sea, however, focus on the larger mega- and macrofauna (Rex \& Etter 2010). A recent review of the $\sim 640$ deepsea (>200 m depth) nematode species known to date shows that 100 species have wide bathymetric ranges $(>1000 \mathrm{~m})$, and 46 are likely to be cosmopolitan (Miljutin et al. 2010), suggesting that species turnover in the deep sea may be limited. On the other hand, studies on continental margins have found high levels of nematode beta diversity across and within ocean basins (Fonseca et al. 2007, Danovaro et al. 2009). Macrohabitat heterogeneity (e.g. canyons, coral degradation zones) in the deep sea influences nematode beta diversity patterns at regional to global scales (Raes \& Vanreusel 2006, Vanreusel et al. 2010), but little is known about the potential influence of sediment characteristics (i.e. microhabitat heterogeneity; Fonseca \& Soltwedel 2009). This lack of information is somewhat surprising given the strong links between sediment physical and chemical characteristics and the composition of benthic communities in shallow habitats (e.g. Vanaverbeke et al. 2011).

Many studies of deep-sea community composition are based on genus or family rather than species data. The paucity of data on the distribution of deepsea species probably reflects the highly labourintensive nature of species identification. Obtaining nematode species distribution data is particularly demanding in deep-sea investigations due to the high abundance, high diversity and the high proportion of undescribed species (Miljutin et al. 2010). These difficulties have led some researchers to explore the use of higher taxonomic levels (i.e. genus, family) as surrogates for species-level information for the study of meiofaunal diversity patterns in shallow marine habitats (e.g. Heip et al. 1988). Several nematode studies have shown that there is minimal loss of ecological information when using genus-level data (e.g. Heip et al. 1988, Somerfield \& Clarke 1995), but few studies have been conducted in the deep sea (Muthumbi et al. 2011). 
Elsewhere we have described patterns of nematode alpha diversity (Leduc et al. 2012b) on the continental slope of New Zealand. Here we compared nematode gamma diversity between 2 regions within the New Zealand Exclusive Economic Zone (Chatham Rise and Challenger Plateau) and investigated patterns of beta diversity within them. In doing so, we aimed to: (1) determine the influence of environmental factors (i.e. sediment characteristics and food availability) on nematode beta diversity; (2) describe spatial patterns in nematode community structure/ composition; and (3) evaluate the effect of using lower taxonomic resolution (i.e. specific vs. generic) on these patterns.

\section{MATERIALS AND METHODS}

\section{Sampling and laboratory methods}

We focussed on 2 main bathymetric features of the New Zealand region, Challenger Plateau and Chatham Rise (SW Pacific Basin; Fig. 1). Challenger Plateau encompasses water depths from ca. 400 to $3000 \mathrm{~m}$ in an area of low biological productivity (Murphy et al. 2001) and low current activity (Heath 1985) to the northwest of the South Island, New
Zealand. Chatham Rise is a submarine ridge extending eastwards from the South Island of New Zealand. It encompasses water depths from ca. 250 to $3000 \mathrm{~m}$ and lies beneath the Subtropical Front (STF), a region associated with heightened primary productivity (Murphy et al. 2001) and high levels of mixing and current activity (Nodder et al. 2007). Productivity is highest on the southern flank of the rise where the STF appears to be bathymetrically locked (Uddstrom \& Oien 1999). Productivity over both Chatham Rise and Challenger Plateau is generally highest in areas closest to the mainland of New Zealand (i.e. eastern Challenger Plateau and western Chatham Rise) and lowest in areas farther offshore (i.e. western Challenger Plateau and eastern Chatham Rise; Murphy et al. 2001). The study area encompassed a wide range of environmental parameters (Table 1) and was wellsuited for examining patterns of turnover beta diversity (sensu Anderson et al. 2011).

Sample sites and sampling methods are described by Leduc et al. (2012b). Briefly, samples were collected along a north-south transect at $178^{\circ} 30^{\prime} \mathrm{E}$ across Chatham Rise (9 sites, 350 to 3100 m water depth) in austral spring (September to October) 2001 during National Institute of Water and Atmospheric Research (NIWA) cruise TAN0116. This transect crossed contrasting productivity regimes on either

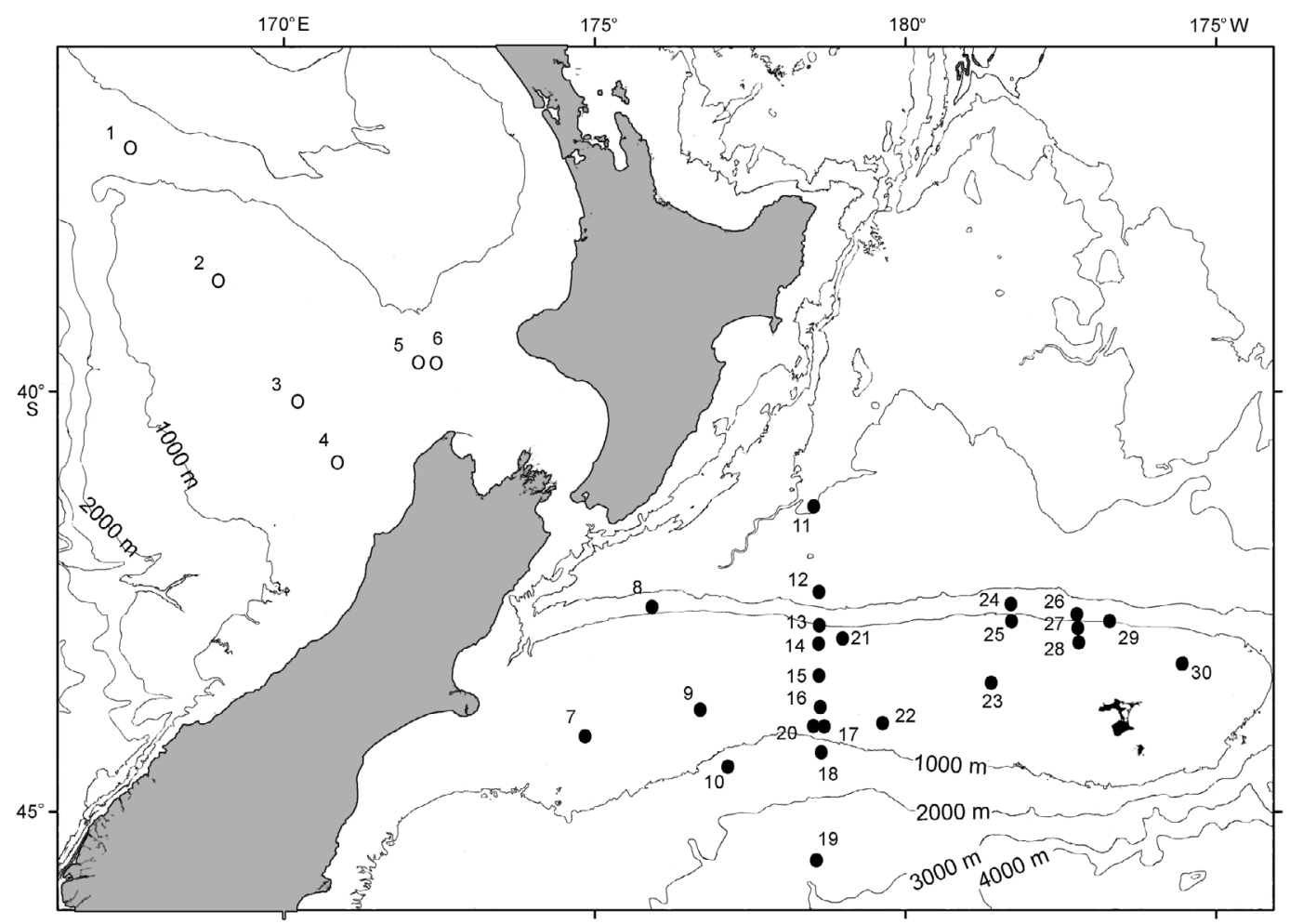

Fig. 1. New Zealand, showing $1000 \mathrm{~m}$ isobaths and location of study sites on the Chatham Rise (bottom right, •) and Challenger Plateau (top left, o) 
Table 1. Number of sites, samples, individuals, species and genera identified on Chatham Rise and Challenger Plateau, range of environmental conditions and estimates of gamma species and genus diversity. The 3 deepest sites (2300-3100 m water depth) sampled on the Chatham Rise are not included in the Chatham Rise column to keep depth ranges comparable between regions. Numbers in brackets are standard deviations of the mean. CPE: chloroplastic pigment equivalents; DW: dry weight; TOM: total organic matter. Chao1 and ACE are abundance-based estimators; Chao2 and ICE are incident-based estimators

\begin{tabular}{|c|c|c|c|}
\hline & $\begin{array}{l}\text { Chatham Rise } \\
(350-1250 \mathrm{~m})\end{array}$ & $\begin{array}{c}\text { Challenger } \\
\text { Plateau } \\
(237-1213 \mathrm{~m})\end{array}$ & $\begin{array}{c}\text { Chatham Rise \& } \\
\text { Challenger Plateau } \\
(237-3100 \mathrm{~m})\end{array}$ \\
\hline No. of sites & 21 & 6 & 30 \\
\hline No. of samples & 23 & 11 & 38 \\
\hline$\%$ silt/clay range & $6-94$ & $35-90$ & $6-97$ \\
\hline$\% \mathrm{CaCO}_{3}$ range & $10-80$ & $26-90$ & $10-100$ \\
\hline$\% \mathrm{H}_{2} \mathrm{O}$ range & $35-54$ & $45-55$ & $35-63$ \\
\hline$\%$ chlorophyll a range & $0-14$ & $0-2$ & $0-14$ \\
\hline $\begin{array}{l}\text { CPE range } \\
\left(\mu g g^{-1} \mathrm{DW} \text { sediment }\right)\end{array}$ & $650-8348$ & $832-3038$ & $594-8348$ \\
\hline$\%$ TOM range & $1-6$ & $2-4$ & $1-7$ \\
\hline No. of individuals identified & 2845 & 1241 & 4546 \\
\hline Singletons (species) & 218 & 136 & 283 \\
\hline Doubletons (species) & 93 & 52 & 130 \\
\hline Recorded species richness & 564 & 307 & 775 \\
\hline Recorded genus richness & 146 & 102 & 162 \\
\hline Chao1 (species) & $820(46)$ & $480(40)$ & $1080(48)$ \\
\hline Chao2 (species) & $899(55)$ & $528(46)$ & $1183(58)$ \\
\hline ACE (species) & 810 & 487 & 1082 \\
\hline ICE (species) & 979 & 601 & 1281 \\
\hline Chao2 (genera) & $156(6)$ & $161(28)$ & $181(9)$ \\
\hline Chao1 (genera) & $156(6)$ & $129(14)$ & $185(13)$ \\
\hline ACE (genera) & 154 & 128 & 175 \\
\hline ICE (genera) & 162 & 141 & 183 \\
\hline
\end{tabular}

from different MUC deployments) per site were obtained for faunal analyses. Each sample consisted of 1 subcore (internal diameter: 26 $\mathrm{mm}$ ) taken to a depth of $5 \mathrm{~cm}$. Samples were fixed in 10\% formalin and stained with Rose Bengal. Samples were subsequently rinsed on a $1 \mathrm{~mm}$ sieve to remove large particles and on a $45 \mu \mathrm{m}$ sieve to retain nematodes. Nematodes were extracted from the remaining sediments by Ludox flotation and transferred to pure glycerol (Somerfield \& Warwick 1996). Extracted samples were mounted onto slides, and between 110 and 150 randomly chosen nematodes (or all individuals if fewer were present in the sample) were identified to genus and putative species using the descriptions in Warwick et al. (1998), as well as the primary literature. Monhystrella and Thalassomonhystera were treated as 1 genus ('Monhysteridae') because they are sometimes difficult to distinguish based on morphology (Fonseca \& Decraemer 2008).

Physical and biogeochemical parameters were measured at the scale of individual MUC cores at side of the rise and provided the opportunity to sample communities under different trophic conditions at comparable depths (Berkenbusch et al. 2011). Twenty-one additional sites (6 on Challenger Plateau and 15 on Chatham Rise, 240 to 1300 m water depth) were sampled in austral autumn to early winter (March to April and May to June) 2007 (NIWA cruises TAN0705 and TAN0707, respectively). Sampling sites were determined based on the subdivision of Chatham Rise and Challenger Plateau into strata derived from multivariate classification of environmental data (Bowden 2011), thereby providing samples from a wide range of environments. The greater number of sites sampled on Chatham Rise relative to Challenger Plateau reflect the greater number of environments thought to exist on the former feature (Nodder et al. 2012). All the sites sampled in the present study were located on the open slope.

Sediment samples were collected using an Ocean Instruments $\mathrm{MC}-800 \mathrm{~A}$ multicorer (MUC; core internal diameter $=9.52 \mathrm{~cm}$ ). One to 3 replicates (i.e. samples all study sites. Methods for the analyses of sediment parameters were given by Nodder et al. (2003) and Grove et al. (2006). These parameters were: chloroplastic pigment equivalents (CPE), proportion of chlorophyll a (chl a) relative to chloroplastic pigment equivalents ( $\% \mathrm{chl} \mathrm{a),} \mathrm{total} \mathrm{organic} \mathrm{matter} \mathrm{content}$ (\% TOM), carbonate content $\left(\% \mathrm{CaCO}_{3}\right)$ and water tified using the percent dry weight of 5 size classes (i.e. $<63,63-125,125-250,250-500,>500 \mu \mathrm{m}$ ).

\section{Statistical analyses}

\section{Gamma diversity}

We determined gamma (regional) diversity for Chatham Rise and Challenger Plateau separately by computing estimates of total species and genera richness using non-parametric estimators. We used both abundance- (i.e. Chao1 and ACE) and incidencebased estimators (Chao2 and ICE) because these content $\left(\% \mathrm{H}_{2} \mathrm{O}\right)$. Sediment granulometry was quan- 
have been shown to perform well in comparative studies (e.g. Foggo et al. 2003) and because agreement between different estimators would suggest a robust result (e.g. Labrune et al. 2006). Estimates of species and genera richness using these estimators were computed using the EstimateS software v8.2.0 (Colwell 1997). Only 3 sites $>1300 \mathrm{~m}$ water depth were sampled $(11,12,19)$, all on Chatham Rise. These sites were omitted from comparisons to ensure comparable depth ranges between regions. Result from species and genus data were compared by plotting randomised, cumulative species richness estimates against number of samples.

\section{Beta diversity}

Beta diversity was calculated as the Bray-Curtis similarity between samples (e.g. Anderson et al. 2011) and represented as percentage similarity. Similarity matrices were computed using both square-root transformed abundance data and presence/absence data because the choice of transformation can have a substantial impact on beta diversity patterns (Anderson et al. 2011). Correlations between the matrices based on square-root and presence/absence data were determined using the RELATE function in PRIMER (Clarke \& Warwick 2001) to examine differences between beta diversity patterns derived from abundance and presence/absence data. The relationship between species and genus similarity matrices was determined in the same way. Preliminary analyses showed no significant differences in community structure and composition between the 2 sampling years (i.e. 2001 and 2007; analysis of similarity [ANOSIM], p > 0.05); therefore, data from both years were combined in the final analyses.

The SIMPER function in PRIMER was used to quantify Bray-Curtis dissimilarity between sites (Clarke \& Warwick 2001) and to provide a basis for comparisons with other studies of nematode beta diversity. Dissimilarities were quantified both within and across the 2 study regions. This analysis was based on 1 replicate per site only to avoid biases arising from the uneven number of replicates per site.

Relationships between spatial and environmental parameters and nematode beta diversity were investigated using distance-based linear models (DistLMs) in PERMANOVA+ (Anderson et al. 2008). The DistLM routine is based on an approach called distance-based redundancy analysis (dbRDA) first developed by Legendre \& Anderson (1999). It is a semi-parametric, permutation-based method that does not rely on the assumption of normally distributed data and is a form of multivariate multiple regression that can be performed directly on a distance or dissimilarity matrix of choice (Anderson et al. 2008). The analyses conducted in DistLM are based on the individual samples, thereby allowing straightforward interpretation of partial regression tests (Anderson et al. 2008). In contrast, other approaches, which treat the individual distances as a single univariate response, are problematic for the interpretation of multiple regression analyses (e.g. the Mantel approach, Anderson et al. 2011). As for the SIMPER analyses, all DistLM analyses were conducted using 1 randomly chosen replicate per site to avoid biases arising from the uneven number of replicates per site. DistLM analyses are not affected by differences in the number of sites between regions (Anderson et al. 2008).

The spatial structure of nematode communities was modelled by building a matrix including the coordinates of each site on an arbitrary grid ( $X$ and $Y$ ), as well as their quadratic $\left(X^{2}, Y^{2}\right)$ and cubic components $\left(X^{3}, Y^{3}\right)$. The inclusion of quadratic and cubic terms allows us to model features such as gaps or patches instead of being limited to simple linear gradients (Borcard et al. 1992). These variables were analysed in a single set (hereafter referred to as 'spatial structure'; Anderson et al. 2008). Because connectivity between Chatham Rise and Challenger Plateau may be limited, we included the factor 'region' as an additional (but separate) spatial variable.

Variability in nematode beta diversity was partitioned according to 2 sets of environmental parameters, i.e. food availability and sediment physicochemical characteristics. Three environmental variables, i.e. CPE, \% chl $a$, and \%TOM, were considered food-related and were analysed together as a single set ('food availability'). The 7 remaining variables, i.e. $\% \mathrm{CaCO}_{3}, \% \mathrm{H}_{2} \mathrm{O}$ and the percentage contribution of the different size classes (i.e. $<63$, 63-125, 125-250, 250-500, >500 $\mu \mathrm{m}$ ) were analysed together in another set ('sediment characteristics'). Two variables were highly correlated (i.e. \% 63-125 and $\left.125-250 \mu \mathrm{m}, \mathrm{R}^{2}>0.9\right)$; therefore, one of these variables (\% 125-250 $\mu \mathrm{m}$ ) was removed from the analysis to avoid co-linearity (Quinn \& Keough 2009).

Water depth is usually considered an environmental variable because it is often correlated with other parameters such as food availability and sediment characteristics. Here we considered water depth as an additional spatial variable (i.e. the third spatial dimension) because more direct proxies of food availability and sediment characteristics were included in the analyses (see above). 
Relationships between spatial and environmental parameters and nematode beta diversity were initially examined by analysing each of the 5 predictors (i.e. spatial structure, region, water depth, food availability and sediment characteristics) separately (marginal tests). We then examined the relationship between beta diversity and the 2 environmental parameters (sediment characteristics and food availability) given the effect of the spatial variables by entering spatial structure, region and water depth as starting terms (Anderson et al. 2008). The step-wise selection procedure was applied for the 2 environmental parameters using adjusted $\left(R_{\text {adj }}^{2}\right)$ as a selection criterion in order to take into account the different number of variables within each parameter (Anderson et al. 2008). We then investigated the relationship between spatial parameters and nematode beta diversity given the effect of environmental parameters by using the same approach (i.e. by entering sediment characteristics and food availability as starting terms, followed by a step-wise selection procedure for the 3 spatial parameters using $R_{\text {adj }}^{2}$ as selection criterion). The p-values for individual predictor variables were obtained using 9999 permutations of raw data (Anderson et al. 2008).

To determine the proportion of total variation explained by the each predictor parameter to the overall model of beta diversity (and to produce a simple illustrative figure), the variability in species and genus beta diversity was partitioned into: (1) 'pure' environmental variation, or the fraction of variation explained by environmental parameters independently of spatial parameters; (2) 'pure' spatial variation, or the fraction of variation explained by spatial parameters independently of environmental parameters; (3) spatially structured environmental variation, or the fraction of variation explained by the combination of environmental and spatial parameters; and (4) unexplained variation, or the fraction of variation not explained by either environmental or spatial parameters in the DistLM models (for details see Borcard et al. 1992). The number of variables we used for spatial (8) and environmental (9) parameters were similar, which allowed meaningful comparisons of explained variation between the 2 parameters (Borcard et al. 1992).

\section{Community composition/structure}

We described the spatial patterns in community composition and structure using hierarchical cluster analysis in PRIMER (Clarke \& Warwick 2001). Simi- larity matrices were built using Bray-Curtis similarity of square-root transformed abundance data and presence/absence data, and all samples (including replicates) were included in the analyses. A similarity profile test (SIMPROF) was performed to identify natural group structure in the samples (Clarke et al. 2008). The SIMPROF routine conducts a series of permutation tests to find clusters of samples with statistically significant internal structure (p set at 0.05 ; Clarke \& Warwick 2001). Results of the SIMPROF analysis were superimposed on a map of the study area for graphical representation. The SIMPER routine in PRIMER was used to identify the taxa contributing most to within-group similarity and between-group dissimilarity (Clarke \& Warwick 2001).

\section{RESULTS}

\section{Gamma diversity}

A total of ca. 4550 individuals belonging to 775 species and 162 genera were identified from the 38 samples taken on Chatham Rise and Challenger Plateau (Table 1). Over half (53\%) of the species were represented by only 1 or 2 individuals, and about a quarter $(23 \%)$ were recorded from both regions. The number of recorded species and genera were higher for Chatham Rise than Challenger Plateau (Table 1). Abundance-based estimators (i.e. Chao1 and ACE) consistently yielded lower estimates of total species richness than incidence-based estimators (Chao2 and ICE) (Table 1). Estimates were broadly consistent, however, with Chao2 estimates usually in the middle range of values. Estimates of total species richness for Chatham Rise (350 to $1250 \mathrm{~m}$ water depth), for example, ranged from 810 to 979 species (Chao2 estimate of 899 species), whilst estimates for Challenger Plateau (237 to $1213 \mathrm{~m}$ ) ranged from 480 to 601 species (Chao2 estimate of 528 species). Plots of randomised, cumulative Chao2 estimates against number of samples show that species curves for each region, and for both regions combined, approached an asymptote, whereas the curve for genera (both regions combined) flattened out at 181 genera after 34 samples (Fig. 2).

\section{Beta diversity}

Comparison between abundance and presence/ absence similarity matrices showed very high correlation for species (RELATE; $\rho=0.98, p=0.001$ ) and, to 


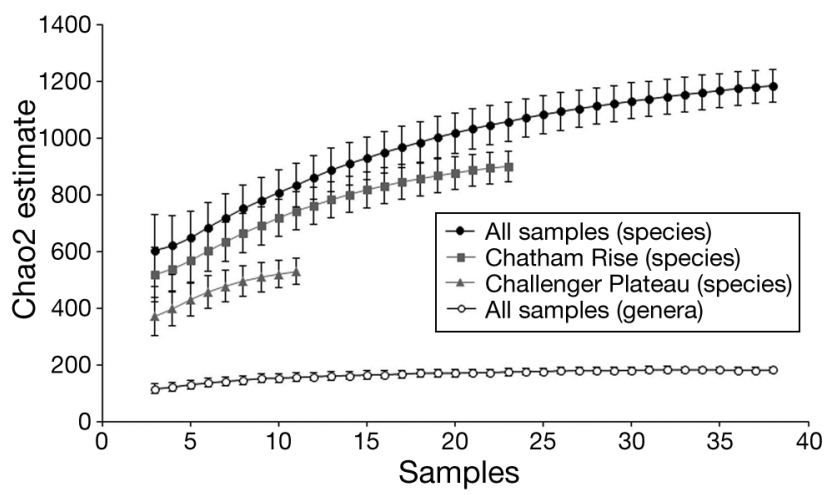

Fig. 2. Plot of randomised, cumulative Chao 2 species and genus richness estimates $( \pm \mathrm{SD})$ against number of samples. The species curve for Chatham Rise excludes samples from the 3 deepest (2300-3100 m water depth) study sites (Sites 11, 12 and 19 in Fig. 1)

a lesser extent, genus data $(\rho=0.92, p=0.001)$. Similarity matrices of species and genus data based on abundance (RELATE, $\rho=0.73, p=0.001$ ) and presence/absence data $(\rho=0.69, p=0.001$ ) were also significantly correlated. Bray-Curtis dissimilarity (square-root transformed data) was slightly greater between the 2 regions (84\%) than within regions (Chatham rise: 83\%; Challenger Plateau: $78 \%$ ) The same pattern was found based on the presence/ absence data $(82,81$ and $76 \%$ dissimilarity, respectively).

Results of DistLM analyses on the influence of spatial and environmental parameters on nematode beta diversity showed similar results for species and genus data (Table 2). Results based on the abundance and presence/absence data were virtually identical; therefore, only the results based on the abundance data are reported and shown. All spatial and environmental parameters were significantly correlated with nematode species and genus beta diversity in marginal tests $(p<0.05)$. The strongest relationships were found for sediment characteristics and spatial structure $\left(\mathrm{R}^{2}=0.30-0.35\right)$, followed by food availability $\left(R^{2}=0.17-0.18\right)$, region $\left(R^{2}=0.06\right)$ and water depth $\left(\mathrm{R}^{2}=0.06\right)$.

The influence of sediment characteristics remained significant in sequential tests after the effect of spatial parameters was taken into account, but food availability was no longer significantly correlated with nematode species and genus beta diversity. Sediment characteristics explained 21 to $23 \%$ of the variability in species and genus beta diversity once the effect of spatial parameters was taken into account (see Table 2). In sequential tests with environmental parameters as starting terms, the effect of spatial structure remained significant for species
Table 2. Result of distance-based linear model (DistLM) analyses showing the influence of spatial (region, spatial structure, water depth) and environmental parameters (sediment physicochemical characteristics, food availability) on nematode species and genus beta diversity (Bray-Curtis similarity of square-root transformed abundance data between sites). Results of the marginal tests show the influence of each parameter in isolation, whereas results of the sequential tests show the effect of environmental parameters on nematode beta diversity in the combined model (stepwise selection with adjusted $\mathrm{R}^{2}\left[\mathrm{R}^{2}{ }_{\text {adj }}\right]$ criterion). Prop.: proportion of total variation explained; Prop (cumul.): Prop. cumulative; Region: Chatham Rise vs. Challenger Plateau; Spatial structure: spatial coordinates and their quadratic and cubic components; Sediment: carbonate content, water content and percentage contribution of 4 different size classes; Food availability: chloroplastic pigment concentration, chlorophyll a content and total organic matter content. -: not applicable; ${ }^{*} \mathrm{p}<0.05$; $^{* *} \mathrm{p}<0.01$

\begin{tabular}{|c|c|c|c|}
\hline Parameter & Prop. & $\begin{array}{c}\text { Prop. } \\
\text { (cumul.) }\end{array}$ & $\begin{array}{c}\mathrm{R}_{\text {adj }} \\
\text { (cumul.) }\end{array}$ \\
\hline \multicolumn{4}{|l|}{ Species } \\
\hline \multicolumn{4}{|l|}{ Marginal } \\
\hline Region $^{* *}$ & 0.06 & - & - \\
\hline Spatial structure ${ }^{* *}$ & 0.30 & - & - \\
\hline Water depth** & 0.06 & - & - \\
\hline Sediment characteristics ${ }^{* *}$ & 0.30 & - & - \\
\hline Food availability ${ }^{* *}$ & 0.17 & - & - \\
\hline \multicolumn{4}{|l|}{ Sequential (spatial first) } \\
\hline $\begin{array}{l}\text { Region }+ \text { Spatial structure }+ \\
\text { Water depth** }\end{array}$ & 0.38 & 0.38 & 0.14 \\
\hline+ Sediment characteristics ${ }^{*}$ & 0.21 & 0.59 & 0.21 \\
\hline + Food availability & 0.06 & 0.68 & 0.23 \\
\hline \multicolumn{4}{|l|}{ Sequential (environmental first) } \\
\hline \multicolumn{4}{|l|}{ Sediment characteristics +} \\
\hline Food availability $^{* *}$ & 0.42 & 0.42 & 0.16 \\
\hline+ Spatial structure* & 0.20 & 0.62 & 0.22 \\
\hline+ Region & 0.03 & 0.65 & 0.22 \\
\hline + Water depth & 0.03 & 0.68 & 0.23 \\
\hline \multicolumn{4}{|l|}{ Genera } \\
\hline \multicolumn{4}{|l|}{ Marginal } \\
\hline Region* & 0.06 & - & - \\
\hline Spatial structure ${ }^{* *}$ & 0.31 & - & - \\
\hline Water depth* & 0.06 & - & - \\
\hline Sediment ${ }^{* *}$ & 0.35 & - & - \\
\hline Food availability $^{* *}$ & 0.18 & - & - \\
\hline \multicolumn{4}{|l|}{ Sequential (spatial first) } \\
\hline Region + Spatial structure + & & & \\
\hline Water depth** & 0.40 & 0.40 & 0.17 \\
\hline+ Sediment characteristics ${ }^{* *}$ & 0.23 & 0.63 & 0.29 \\
\hline + Food availability & 0.07 & 0.70 & 0.27 \\
\hline \multicolumn{4}{|l|}{ Sequential (environmental first) } \\
\hline Sediment characteristics + & & & \\
\hline Food availability $^{* *}$ & 0.45 & 0.45 & $\begin{array}{l}0.20 \\
0.24\end{array}$ \\
\hline $\begin{array}{l}\text { + Spatial structure } \\
\text { + Region }\end{array}$ & 0.18 & 0.63 & $\begin{array}{l}0.24 \\
0.26\end{array}$ \\
\hline + Water depth & 0.03 & 0.70 & 0.27 \\
\hline
\end{tabular}


beta diversity, but not genus beta diversity. Region and water depth were not significantly correlated with either species or genus beta diversity after the effect of environmental parameters was taken into account. Variation in nematode species and genus beta diversity in models combining all variables was partitioned as follows: (1) pure environmental variation: $30 \%$; (2) pure spatial variation: $25-26 \%$; (3) spatially structured environmental variation: $12-15 \%$; (4) unexplained variation: 30-32\% (Fig. 3).

\section{Community composition/structure}

Hierarchical cluster analysis based on abundance and presence/absence of species showed the same patterns and revealed 9 significant groups (SIMPROF, $\mathrm{p}<0.05$, Fig. 4); the following describes results based on the abundance data only. The 9 SIMPROF groups can be categorised into 5 broader, mainly location-based, 'communities' (CP, CR1, CR2, CR3) and 1 independent site (Site 19). CR1 was separated from the other communities at the $11 \%$ similarity level, and comprised 3 adjacent sites situated on the north-eastern Chatham Rise (799-980 m water depth, Fig. 5). These sites were characterised by the lowest silt/clay content of all the sites we sampled (6-7\%, compared to $23-97 \%$ at the other sites). CR2 was separated from $\mathrm{CP}$ and CR3 at the $17 \%$ similarity level and consisted of the 2 deepest sites (2300 and $3100 \mathrm{~m}$ water depth) on the northern flank of the Chatham Rise. These sites were characterised by the

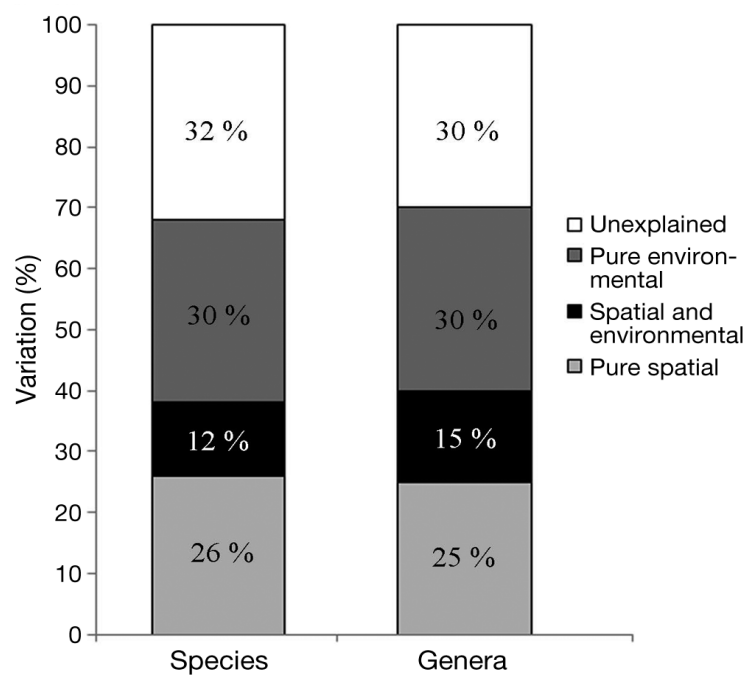

Fig. 3. Variation partitioning of nematode species and genus beta diversity similarity matrices computed using BrayCurtis similarity of square-root transformed abundance data. See Table 2 for results of distance-based linear model (DistLM) analyses finest sediments of the sites we sampled $(95-97 \%$ silt/clay). CP and CR3 were separated at the $19 \%$ similarity level, and included the remaining sites from the Challenger Plateau and Chatham Rise, respectively, except for Site 10 (Chatham Rise), which was classified with the Challenger Plateau sites. CR3 was divided into an east (CR3E, 422-1200 m) and west sub-community (CR3W, 350-1210 m). Similarly, $\mathrm{CP}$ was divided into east (CPE, 237-804 m) and west sub-community (CPW, 480-1240 m).

Analysis of genus data showed some differences with the results of the species analysis, and contrasting results depending on the type of data used. The SIMPROF procedure based on the abundance data revealed 5 genera groups, which were categorised into 4 genera communities. Two of these communities corresponded to CR1 and CR2 identified from the species data, whereas the other 2 both represented a mixture of sites from CP and CR3 (Fig. 4). In contrast, only 2 SIMPROF groups were identified based on presence/absence data (not shown). One group corresponded to CR1 identified from the species data, and the other group included all other sites (except Site 18, which was not grouped).

The 5 species contributing the most to the faunal similarity of each species-based community are shown in Table S1 in the Supplement; www.int-res. com/articles/suppl/m454p037_supp.pdf. CR1 was the most distinct group identified from the hierarchical cluster analyses; about a third of the overall similarity within this group was accounted for by the species Actinonema sp. 3, Calomicrolaimus spp. 2 and 4, and Microlaimus sp. 17. Diplopeltula sp. 2, Greeffiella sp. 3 and Halalaimus sp. 7 accounted for much of the similarity of CR2. Paramonohystera sp. 1 contributed to the similarity of the sub-communities CR3W, CR3E and CPE, whereas Theristus sp. 9 was the highest contributor to the similarity sub-community CPW. The dissimilarity between CR1 and all other communities could be partly explained by the absence in the former of Paramonohystera sp. 1 and Sabatieria bitumen (Table S2 in the Supplement). Low abundance of these species within CR2 also contributed to the dissimilarity between this community and CP and CR3. The CP community could be distinguished from CR3 based on the relatively high abundance of S. bitumen, Theristus sp. 9 and Sabatieria sp. 16 in the former. The same species also accounted for much of the dissimilarity between CPW and CPE. High abundance of Molgolaimus sp. 6, Gammanema sp. 1, S. bitumen and Vasostoma sp. 1 in CR3E relative to CR3W contributed to the dissimilarity between these communities. 

SIMPROF analyses of (a) species and (b) genus similarity matrices computed using Bray-Curtis similarity of square-root transformed abundance data. Significant groups $(p<0.05)$ are shown by (a) coloured (species groups) and (b) grey vertical bars (genera groups). Ungrouped samples are shown in black. Communities and sub-communities are identified by the thick horizontal lines below each cluster diagram. Numbers refer to sites shown in Fig. 1. CP: Challenger Plateau; CR: Chatham Rise; E: east; W: west
Fig. 4. Results of cluster and
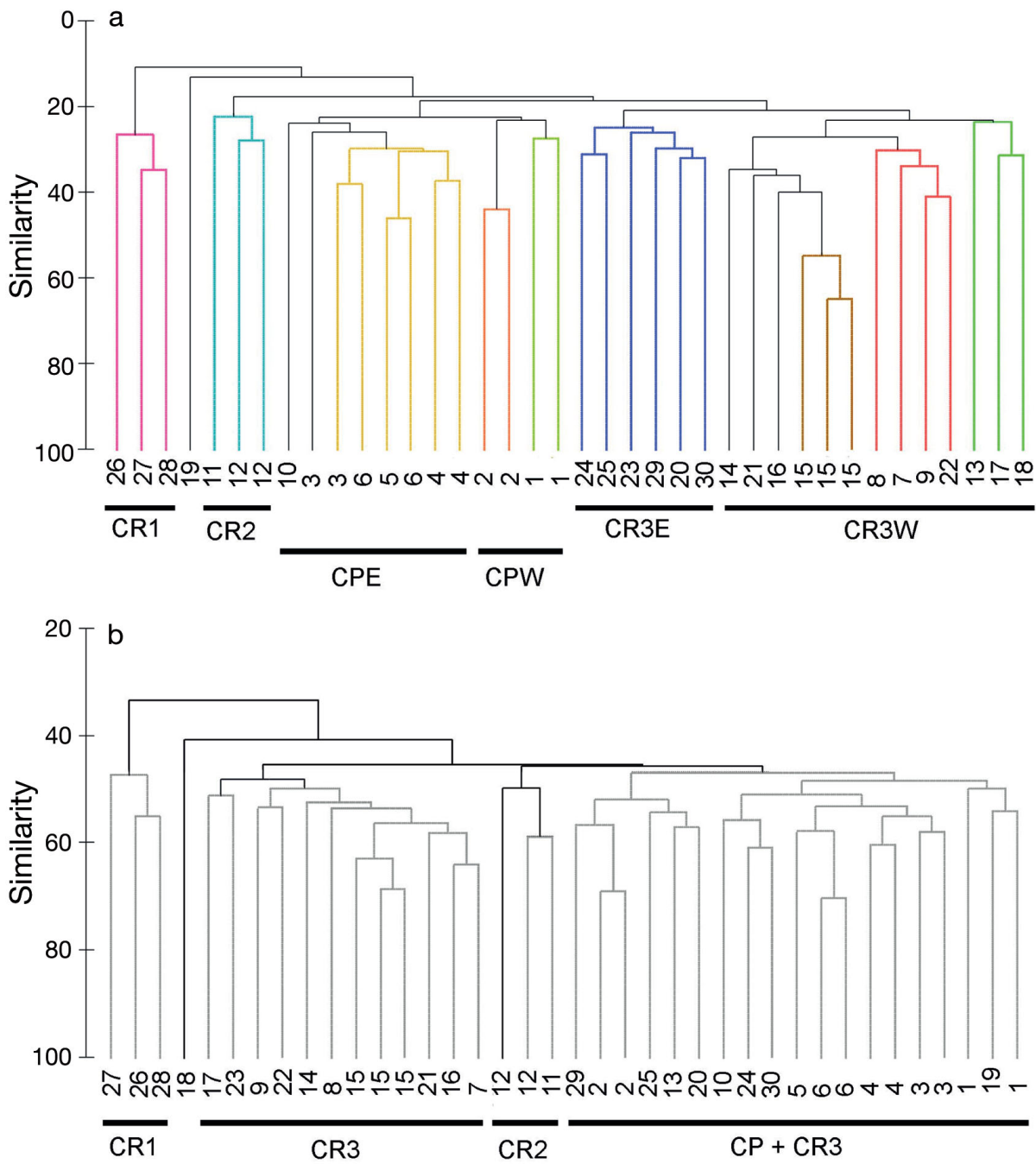

\section{DISCUSSION}

The 5 genera contributing the most to the faunal similarity of the CR1 and CR2 communities are shown in Table S3 in the Supplement. About a third of the overall similarity within CR1 was accounted for by the genera Calomicrolaimus, Theristus and Monhystrella/Thalassomonhystera ('Monhysteridae'). Monhystrella/Thalassomonhystera, Acantholaimus and Desmoscolex accounted for a similar proportion of the similarity of CR2. The dissimilarity between CR1 and the other communities could be partly explained by the low abundance of Sabatieria and Monhystrella/ Thalassomonhystera in the former (Table S4 in the Supplement). We also noted the presence of the typically shallow water genera Rynchonema, Xyala and Gonionchus at CR1 (2-4\% of total abundance); these were absent from all other sites we sampled. Low abundance of Sabatieria, as well as high abundance of Monhystrella/Thalassomonhystera and Acantholaimus within CR2 contributed to the dissimilarity between this and the other communities.

\section{Gamma diversity}

The number of species recorded from the study areas on the continental slope of New Zealand appears to be relatively high, although comparison with other continental margins is difficult due to differences in sampling effort and processing methods (Table 3). The number of species recorded on Chatham Rise, for example, is higher than recorded from other regions such as the North Atlantic, but this difference probably reflects the limited depth range sampled in the latter (Fonseca \& Soltwedel 2009). In addition, sediment depth can have a major influence on nematode community composition (Giere 2009), and studies limited to surface sediments (e.g. Danovaro et al. 2009) are likely to substantially underestimate diversity relative to studies sampling deeper into the sediments (Leduc et al. 2010). 


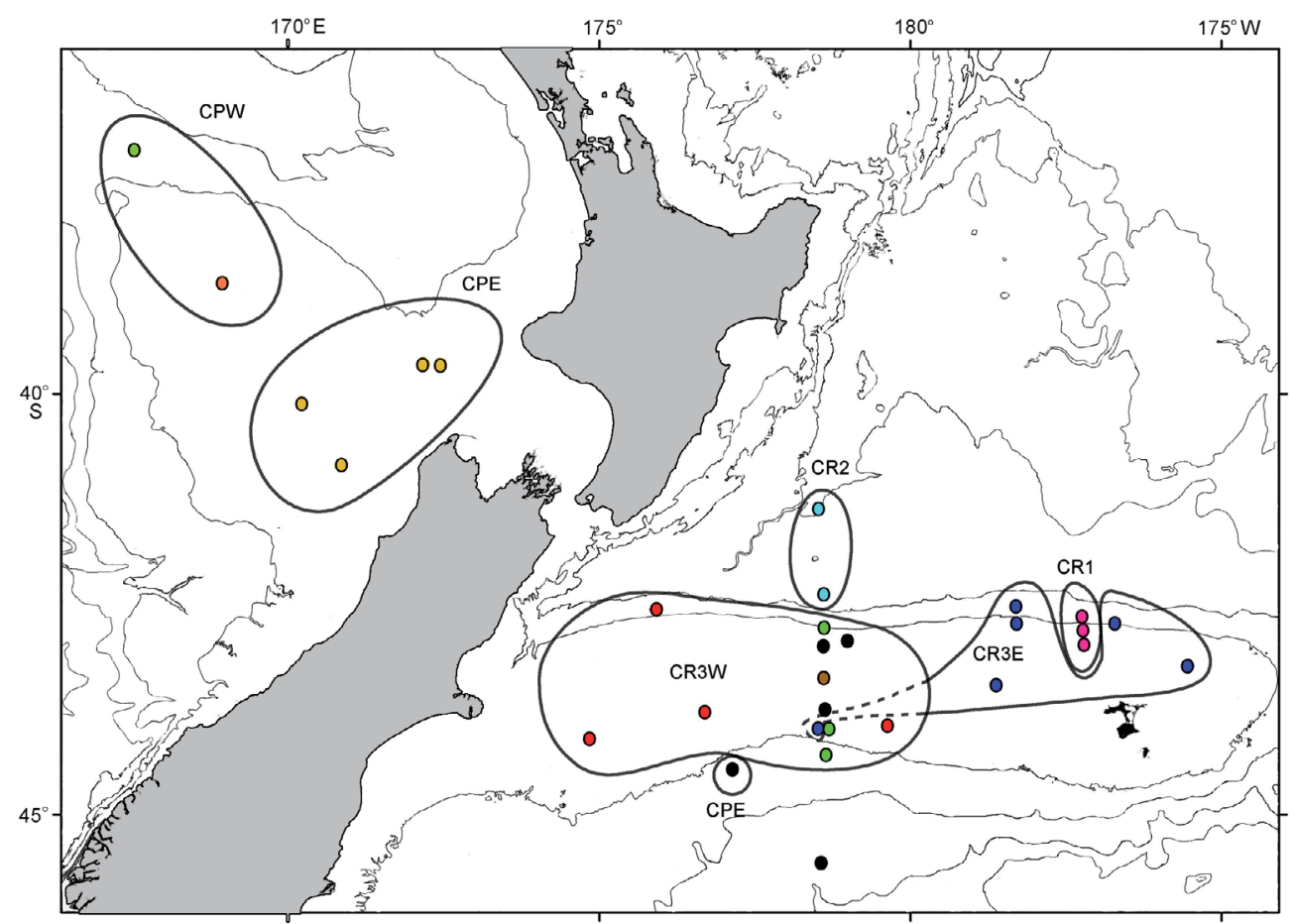

Fig. 5. Study sites, showing significant species groups $(\mathrm{p}<0.05)$ identified from a similarity profile test (SIMPROF) analysis. Each group is identified by a colour, and ungrouped sites are shown in black. Species communities and sub-communities identified from cluster diagrams (CR1, CR2, CR3E, CR3W, CPE and CPW) are also shown. See Fig. 4 for abbreviations and details of cluster analysis

Our estimates of total species richness (gamma diversity) based on the Chao2 method are likely to be conservative because species accumulation curves did not quite reach an asymptote. Ellingsen \& Gray (2002) also showed that this method can underestimate species richness by a factor of 2.5 . Total nematode species richness in the study areas on the continental slope of New Zealand may, therefore, be considerably higher than our estimate of 1183 species. Total species richness on Chatham Rise (350-
$1250 \mathrm{~m}$ depth; 899 species) was almost twice that of Challenger Plateau (237-1213 m; 528 species). This difference is probably the result of the greater range of environmental conditions encompassed by Chatham Rise (see Table 1) and the greater number of sites sampled there (21 sites) relative to Challenger Plateau (6 sites). In contrast, Chao2 estimates of total genus richness reached an asymptote at 181 genera, and were similar between the 2 regions, suggesting similar levels of generic gamma diversity. This lack of

Table 3. Total nematode species richness in bathyal habitats. $N$ : number of individuals identified; $S$ : observed number of species; NS: not specified

\begin{tabular}{|lcccccc|}
\hline Region & Water depth $(\mathrm{m})$ & No. sites & No. samples & $N$ & $S$ & Source \\
\hline Mediterranean & $196-2342$ & 23 & 69 & NS (<6900) & $255^{\text {a }}$ & Danovaro et al. (2009) \\
NE Atlantic & $416-4987$ & 21 & 63 & NS $(<6300)$ & $355^{\text {a }}$ & Danovaro et al. (2009) \\
North Atlantic & 2000 & 8 & 24 & NS & 406 & Fonseca \& Soltwedel (2009) \\
Rockall Trough & $545-1474$ & 3 & 9 & 304 & $80^{\text {a }}$ & Lambshead et al. (1994) \\
Mediterranean & 990 & 1 & 2 & 808 & 190 & Soetaert \& Heip (1990) \\
San Diego Trough & 1050 & 1 & 6 & 1355 & $116^{\text {a }}$ & Lambshead et al. (1994) \\
Fram Strait & 2500 & 1 & 12 & $\sim 1360$ & $202^{\text {b }}$ & Gallucci et al. (2008) \\
Fram Strait & 1300 & 1 & 3 & $\sim 3430$ & $176^{\text {a }}$ & Gallucci et al. (2009) \\
Chatham Rise & 1240 & 1 & 6 & 1500 & 247 & Leduc et al. (2010) \\
Chatham Rise & $350-3100$ & 24 & 38 & 3305 & 645 & Present study \\
Challenger Plateau & $237-1213$ & 6 & 11 & 1241 & 307 & Present study \\
a Only top 1 cm of sediment was analysed; ${ }^{b}$ only top 2 cm of sediment were analysed & \\
\hline
\end{tabular}


difference between regions may reflect the wide distribution of most deep-sea nematode genera and their generally low level of environmental specificity (Vanreusel et al. 2010).

Lambshead \& Boucher (2003) suggested that, whilst deep-sea nematode diversity may be very high at the local scale, diversity at the regional scale is relatively limited. The information available to date appears to support this suggestion. Several studies have shown high nematode species richness (116 to 202 species) at single bathyal sites, although these are likely to be underestimates since only surface $(\leq 2 \mathrm{~cm})$ sediments were analysed (Lambshead et al. 1994, Gallucci et al. 2008, 2009). On the Chatham Rise, a comprehensive survey of nematode species at 1 site yielded 247 species $(0-5 \mathrm{~cm}$ sediment depth, Leduc et al. 2010), which is equivalent to more than a third of all species recorded from 24 sites in the region (see Table 3). Low or comparable levels of regional diversity in bathyal relative to coastal habitats (despite the greater local diversity in the former) may be related to the lack of dispersal barriers and/or relatively low macrohabitat heterogeneity in deeper waters (Lambshead \& Boucher 2003). The contribution of macrohabitat heterogeneity to regional diversity of deep-sea nematodes, however, may have been underestimated (Zeppilli et al. 2011).

\section{Beta diversity}

Our analyses based on nematode species and genus data yielded very similar relationships between environmental parameters and nematode beta diversity. Nematode genus beta diversity, however, was not significantly correlated with spatial parameters after the effect of environmental parameters was taken into account, suggesting that, unlike species data, genus beta diversity primarily reflects environmental influences and is not spatially structured. As noted above, most deep-sea genera have low environmental specificity and tend to be widely distributed (Vanreusel et al. 2010), which may explain this discrepancy. These results suggest that genus data can be used to determine environmental drivers of deep-sea nematode beta diversity without noticeable loss of information. In contrast, a study on the Kenyan margin found differences in patterns of nematode genus and species diversity (Muthumbi et al. 2011). The latter study, however, was restricted to 3 nematode families, which could explain this discrepancy.
Partitioning of variation in nematode species beta diversity showed that a substantial proportion of the variation was explained by pure spatial variation $(26 \%)$, indicating that some unmeasured underlying processes are affecting nematode species beta diversity patterns. Much of this pure spatial variation was accounted for by spatial structure, which explained $20 \%$ of the variability in nematode species beta diversity in sequential tests (see Table 2). While these results do not tell us anything about the underlying mechanisms (Anderson et al. 2011), they indicate that a sizeable proportion of the variation in species beta diversity is associated with processes at the scale of our spatial structure variable. To some extent, these findings may reflect our sampling strategy for NIWA cruises TAN0705 and TAN0707 (see 'Materials and methods'), which was developed to maximise the range of environments sampled based on oceanographic data layers and parameters from multi-beam echo-sounder transects (Bowden 2011, Nodder et al. 2012). The relationship between spatial structure and nematode species beta diversity could, therefore, suggest an influence of environment at scales beyond that of the individual sediment cores at which detailed environmental measurements were made here. Irrespective of what the underlying mechanisms may be, our results suggest that future studies should focus on nematode diversity in relation to processes operating across a range of wider scales.

Our results showed high mean Bray-Curtis dissimilarity between the Chatham Rise and Challenger Plateau (82-84\%, depending on whether abundance or presence/absence data were used). A study by Danovaro et al. (2009) on deep-sea nematode species communities found high levels of dissimilarity between the western and central Mediterranean (83\%), and between the Portuguese and Mediterranean margins $(90 \%)$; another study also found high dissimilarity between the eastern and western Mediterranean (75\%; Danovaro et al. 2008). Mean Bray-Curtis dissimilarity between regions in the present study, however, was only marginally $(1-6 \%)$ greater than within-region dissimilarity. In addition, results of DistLM analyses showed that the spatial factor 'region' explained only a small proportion $\left(\mathrm{R}^{2}=0.06\right)$ of the variability in nematode beta diversity. Deep-sea nematode species can disperse over large distances (i.e. $100-1000 \mathrm{~km}$ ) despite their limited ability to swim and lack of pelagic larvae, and the limited evidence available to date suggests that some species are widely distributed across continental margins (Fonseca \& Soltwedel 2009) and ocean basins (Miljutin et al. 2010). Potential for passive dispersal is 
likely to be high on the Chatham Rise, where tidally driven currents are strong enough to regularly resuspend recently settled phytodetritus (Nodder et al. 2007), and in the vicinity of Cook Strait (which separates the 2 study regions), where very strong tidally generated currents can presumably transport individuals between the 2 regions. The high dissimilarity observed between the Chatham Rise and Challenger Plateau, therefore, was not related to regional differences in nematode species composition but to factors acting at smaller (i.e. among-site) spatial scales.

When taking into account the spatial structure of nematode communities, our findings indicate that the physicochemical characteristics of the sediments were the main environmental drivers of both species and genus beta diversity on the continental slope of New Zealand. Several studies have shown the strong influence of sediment characteristics on nematode community structure in shallow marine habitats (e.g. Merckx et al. 2009, Vanaverbeke et al. 2011). However, few studies have investigated the relationship between sediment physico-chemical characteristics and nematode beta diversity in the deep sea (e.g. Fonseca \& Soltwedel 2009). The potential influence of sediment granulometry on nematodes, in particular, is seldom investigated, perhaps because variation in sediment grain size is (or is assumed to be) lower in the deep sea than in shallower environments. In the present study, a wide range of sediment grain sizes was sampled, which probably increased the likelihood of finding significant relationships relative to studies limited to a narrower range of grain sizes. Similarly, a large-scale study on the Norwegian continental shelf spanning a wide range of grain sizes showed that sediment granulometry was a major driver of macroinfaunal beta diversity (Ellingsen \& Gray 2002). These findings suggest that variation in the physico-chemical structure of soft sediment habitats (i.e. microhabitat heterogeneity) is an important factor influencing beta diversity of the benthos. The key influence of larger features at the $\geq \mathrm{m}$ scale (i.e. macrohabitat heterogeneity) on diversity has repeatedly been demonstrated (see review by Rosenzweig 1995); quantifying microhabitat heterogeneity and its influence on community composition or structure in the apparently homogeneous expanses of marine soft sediments, however, is challenging. The main impediment to quantifying microhabitat heterogeneity in soft sediments is the usually gradual nature of change in sediment characteristics, making any clear distinction between habitats difficult on the open slope or vast expanses of the abyss. Our results show that gradual variation in sediment characteristics over a sufficiently wide range can lead to distinct faunal communities (see next section) in soft-substratum environments. Assessing levels of microhabitat heterogeneity in deep-sea habitats should, therefore, be considered in addition to more easily observed macrohabitat heterogeneity.

In contrast, food availability did not appear to play a significant role in determining patterns of beta diversity at the study areas on the continental slope of New Zealand. This result may seem surprising given the gradients in productivity encompassed by the sampling, and a previous finding for the same areas suggests a significant unimodal relationship between productivity and nematode alpha diversity (Leduc et al. 2012a, this volume). Patterns of beta diversity, however, describe the variation in community composition/structure rather than the number of co-existing species. Thus, alpha and beta diversity trends are not necessarily influenced by the same environmental factors. In addition, highly oligotrophic habitats (e.g. abyssal plain) were not included in our analyses, which may have affected our results. Some authors, however, have observed different genus assemblages in deep-sea areas characterised by similar productivity (i.e. the abyssal NE and NW tropical Atlantic), suggesting that productivity is not always the primary driver of deep-sea nematode beta diversity (Vanreusel et al. 2010).

\section{Community composition/structure}

The number of communities identified by the hierarchical cluster analyses and SIMPROF depended on taxonomic resolution and, for the genus data, on the type of data used (abundance vs. presence/absence). All analyses identified the CR1 community as being distinct from the rest, while the CR2 community was identified in all analyses except that of genus presence/absence data. Thus, although there was some degree of consistency between the different methodologies, species data yielded a greater number of communities relative to genus data, indicating that species-level information allows greater discrimination between communities. Consequently, we suggest that species-level information is preferable for identifying communities for management and conservation purposes.

CR1 was the most distinct group identified from the hierarchical cluster analyses. Species of some genera, such as Rynchonema, Xyala and Gonionchus, were relatively common in CR1, but were absent everywhere else. These genera are usually found in 


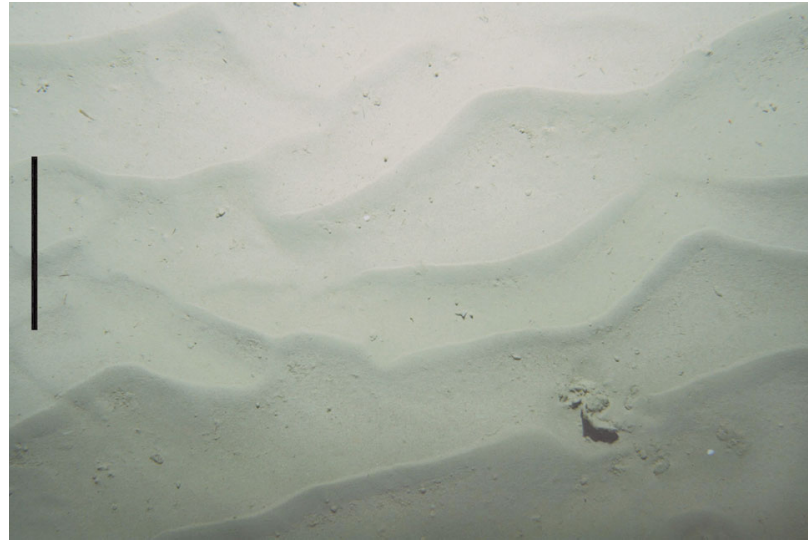

Fig. 6. Seabed photo taken at Site 27 on northeastern Chatham Rise (895 $\mathrm{m}$ water depth) showing presence of sand ripples. Scale bar $=20 \mathrm{~cm}$

exposed intertidal or subtidal sandy sediments (e.g. Vincx \& Furstenberg 1988, Ellis et al. 2011), and their presence in deep-sea sediments was unexpected. Conversely, genera that were dominant at most other sites (i.e. Sabatieria, Monhystrella/Thalassomonhystera) were relatively rare at CR1. Sediments at the 3 sites comprising the CR1 community were characterised by coarse grain size (93-94\% sand), and seabed photographs of these sites show the presence of sand ripples, suggesting strong hydrodynamic conditions (Fig. 6). These findings indicate that the environmental conditions at the CR1 sites may be similar to those more typically found in shallow habitats, which may explain why the CR1 community is so distinct from all other sites we sampled.

The CR2 community was characterised by the relatively low abundance of species of the genus Sabatieria, a genus usually most abundant in fine sediments with high organic matter content (e.g. Soetaert \& Heip 1995, Vanaverbeke et al. 2011). On the other hand, species of Acantholaimus and Monhystrella/ Thalassomonhystera were more abundant in this community than at the other sites. These genera dominate abyssal nematode communities where organic matter input is much lower than on the continental slope (Vanreusel et al. 2010). In addition, the relative abundance of Acantholaimus typically increases with water depth and is inversely correlated with organic matter input (Soetaert \& Heip 1995, De Mesel et al. 2006). Thus, the distinction between CR2 and the other communities probably reflects the environmental conditions typical of lower slope environments (i.e. low productivity and fine sediments).

Differences in the composition of nematode taxa between sub-communities identified from species data are more difficult to interpret due to the general lack of information on the ecology of deep-sea species. Distinctions between sub-communities were also more subtle than between communities, reflecting the greater faunal similarity of the former. Some tentative inferences, however, may be made based on the distribution of closely related species. The relatively high abundance of Hopperia and Paramonohystera spp. in the CPE sub-community relative to CPW on the Challenger Plateau, for example, may reflect the generally shallow water depth preferences of these genera (i.e. coastal and upper slope; Chen \& Vincx 1998, 2000, Miljutin et al. 2010). Theristus, in contrast, has been described as a deepsea genus (e.g. Soetaert \& Heip 1995). Thus, the greater abundance of Theristus sp. 9 at CPW than at CPE may reflect the lower productivity at sites farther offshore (Murphy et al. 2001).

The distribution of the nematode communities identified by the present study can be compared with the results of previous studies for macrofauna. Probert et al. (1996) identified 2 infaunal polychaete communities on the Chatham Rise: a deep (802$1394 \mathrm{~m}$ ) community that occurred on the northern and southern flanks of the central part of the rise, and a shallower (244-1048 m) community that occurred between the deep flanks. A more recent study by Probert et al. (2009) identified an infaunal polychaete community on the crest of Chatham Rise and another community at $750 \mathrm{~m}$ on the southern flank of the rise, whilst polychaete assemblages at deeper sites (981$2330 \mathrm{~m}$ ) on either flank of the rise were highly heterogeneous. Three epibenthic macrofauna communities were distinguished on the Chatham Rise by McKnight \& Probert (1997); the spatial pattern was similar to that for infaunal polychaetes. The most homogeneous of these communities occurred on the muddy sands of the crest and shallower flanks (237-602 m) of the rise. The other 2 generally depthstratified communities were found both sides of the rise, but at deeper depths on the northern flank (625-1693 $\mathrm{m}, 462-665 \mathrm{~m}$ ) than on the southern flank (1491-2039 m, 799-1963 m). Where the area covered by these 2 macrofauna studies overlaps with the present study (the central transect on the Chatham Rise), the spatial distribution of nematode communities is broadly similar to that of the macrofauna. A recent study of the hyperbenthic macrofauna by Lörz (2010), using data from some of the same sites as the present study from both Chatham Rise and Challenger Plateau, found that assemblages from the 2 regions were not different. This result contrasts with the weak but significant difference we described between these regions for nematode species and genus 
communities. This discrepancy may reflect the relatively coarse taxonomic resolution (order, class, phylum) used by Lörz (2010).

SIMPROF results based on nematode species data yielded 9 distinct groups, suggesting a relatively high level of heterogeneity in nematode community composition/structure at our study sites. The western and central Chatham Rise areas were particularly heterogeneous and included 5 of these groups. This pattern may reflect a greater turnover of species within the western and central Chatham Rise areas than elsewhere or may have resulted from the greater density of sampling sites in these areas. The presence of 5 distinct and interspersed groups in these areas, however, would be difficult to accommodate in a workable conservation/management scheme. The more subjective grouping of the study sites into 6 broad communities and sub-communities would provide a more practical basis for spatial management of the seabed, but ignores much of the heterogeneity in the western/central Chatham Rise areas. The usefulness of the present subdivision of the study area based on nematode species data for management/conservation purposes is currently being assessed by comparing it to results of analyses based on data for other faunal groups (i.e. macrofauna, epibenthic megafauna) from the majority of the same sites (e.g. Knox et al. 2012). This study will include an evaluation of the representation of different seafloor communities by the current benthic protected areas on the Chatham Rise and Challenger Plateau (Helson et al. 2010), and the distribution of communities relative to areas covered by prospecting permits for mining of phosphorite nodules on the Chatham Rise (www.nzpam.govt.nz/cms/minerals/permits) and exploration permits for petroleum and gas on the edge of the Challenger Plateau (www.nzpam.govt.nz/ cms/petroleum/permits-content).

Acknowledgements. Sample data were generated under the Foundation for Research, Science and Technology (FRST) programme 'Ocean Ecosystems' (C01X0027) and the Ocean Survey 20/20 Chatham-Challenger project for which we thank the funding agencies, Land Information New Zealand, Ministry of Fisheries, Department of Conservation and NIWA, for permission to use the data. Funding was also provided by FRST through a postdoctoral fellowship to D.L. (UOOX0909), the programmes 'Consequences of EarthOcean Change' (C01X0702), 'Coasts \& Oceans OBI' (C01X0501) and 'Impact of resource use on vulnerable deep-sea communities' (CO1X0906). Acknowledgement is also given to ALW-NOW (subsidy 835.20.008 to 'Frontal Organic Matter Governing ecosystem Structure [FROGS]') and Royal Netherlands Academy of Arts and Sciences (KNAW) for a grant to R.W. (SBP/JK 2001-10). We thank K.
Berkenbusch for processing meiofauna samples (TAN0116). We also thank the other participants of NIWA voyages TAN0116, TAN0705 and TAN0707, and the officers and crew of RV 'Tangaroa'. We are grateful for the constructive criticisms provided by 3 anonymous reviewers.

\section{LITERATURE CITED}

Anderson MJ, Gorley RN, Clarke KR (2008) PERMANOVA+ for PRIMER: guide to software and statistical methods. PRIMER-E, Plymouth

Anderson MJ, Crist TO, Chase JM, Vellend M and others (2011) Navigating the multiple meanings of $\beta$ diversity: a roadmap for the practicing ecologist. Ecol Lett 14:19-28

Baguley JG, Montagna PA, Hyde LJ, Rowe GT (2008) Metazoan meiofauna biomass, grazing, and weight-dependent respiration in the Northern Gulf of Mexico deep sea. Deep-Sea Res I 55:2607-2616

> Berkenbusch K, Probert PK, Nodder SD (2011) Comparative biomass of sediment benthos across a depth transect, Chatham Rise, Southwest Pacific Ocean. Mar Ecol Prog Ser 425:79-90

Blake JA, Grassle JF (1994) Benthic community structure on the U.S. South Atlantic slope off the Carolinas: spatial heterogeneity in a current-dominated system. Deep-Sea Res II 41:4-6

> Borcard D, Legendre P, Drapeau P (1992) Partialling out the spatial component of ecological variation. Ecology 73: 1045-1055

Bowden DA (2011) Benthic invertebrate samples and data from the Ocean Survey 20/20 voyages to Chatham Rise and Challenger Plateau, 2007. Aquatic environment and biodiversity. Report No. 65. Ministry of Fisheries, Wellington

Cartes JE, Jaume D, Madurell T (2003) Local changes in the composition and community structure of suprabenthic paracarid crustaceans on the bathyal Mediterranean: influence of environmental factors. Mar Biol 143:745-758

> Chen G, Vincx M (1998) Nematodes from the Strait of Magellan and the Beagle Channel (Chile): description of four new species of Comesomatidae. Hydrobiologia 379: 97-110

Chen G, Vincx M (2000) New and little known nematodes (Monhysteroida, Nematoda) from the Strait of Magellan and the Beagle Channel (Chile). Hydrobiologia 429:9-23

Clarke KR, Warwick RM (2001) Change in marine communities: an approach to statistical analysis and interpretation, 2nd edn. PRIMER-E, Plymouth

> Clarke KR, Somerfield PJ, Gorley RN (2008) Testing of null hypotheses in exploratory community analyses: similarity profiles and biota-environment linkage. J Exp Mar Biol Ecol 366:56-69

Colwell RK (1997) EstiMateS: statistical estimation of species richness and shared species from samples. Version 8.2.0. University of Connecticut, Storrs, CT. Available at http://viceroy.eeb.uconn.edu/estimates

> Danovaro R, Gambi C, Lampadariou N, Tselepides A (2008) Deep-sea nematode biodiversity in the Mediterranean basin: testing for longitudinal, bathymetric and energetic gradients. Ecography 31:231-244

Danovaro R, Bianchelli S, Gambi C, Mea M, Zeppilli D (2009) $\alpha-, \beta-, \gamma-, \delta$ - and $\varepsilon$-diversity of deep-sea nematodes in canyons and open slopes of Northeast Atlantic and Mediterranean margins. Mar Ecol Prog Ser 396:197-209 
De Mesel I, Lee HJ, Vanhove S, Vincx M, Vanreusel A (2006) Species diversity and distribution within the deepsea nematode genus Acantholaimus on the continental shelf and slope in Antarctica. Polar Biol 29:860-871

Ellingsen KE, Gray JS (2002) Spatial patterns of benthic diversity: Is there a latitudinal gradient along the Norwegian continental shelf? J Anim Ecol 71:373-389

Ellis JR, Maxwell T, Schratzberger M, Rogers SI (2011) The benthos and fish of offshore sandbank habitats in the southern North Sea. J Mar Biol Assoc UK 91:1319-1335

Foggo A, Attrill MJ, Frost MT, Rowden AA (2003) Estimating marine species richness: an evaluation of six extrapolative techniques. Mar Ecol Prog Ser 248:15-26

Fonseca G, Decraemer W (2008) State of the art of the freeliving marine Monhysteridae (Nematoda). J Mar Biol Assoc UK 88:1371-1390

Fonseca G, Soltwedel T (2009) Regional patterns of nematode assemblages in the Arctic deep seas. Polar Biol 32: 1345-1357

> Fonseca G, Muthumbi AW, Vanreusel A (2007) Species richness of the genus Molgolaimus (Nematoda) from local to ocean scale along continental slopes. Mar Ecol 28: 446-459

Galéron J, Menot L, Renaud N, Crassous P, Khripounoff A, Treignier C, Sibuet M (2009) Spatial and temporal patterns of benthic macrofaunal communities on the deep continental margin in the Gulf of Guinea. Deep-Sea Res II 56:2299-2312

Gallucci F, Fonseca G, Soltwedel T (2008) Effects of megafauna exclusion on nematode assemblages at a deep-sea site. Deep-Sea Res I 55:332-349

Gallucci F, Moens T, Fonseca G (2009) Small-scale spatial patterns of meiobenthos in the Arctic deep sea. Mar Biodivers 39:9-25

Giere O (2009) Meiobenthology: the microscopic motile fauna of aquatic sediments, 2nd edn. Springer-Verlag, Berlin

> Gooday AJ, Bett BJ, Escobar E, Ingole B and others (2010) Habitat heterogeneity and its influence on benthic biodiversity in oxygen minimum zones. Mar Ecol 31:125-147

> Grove SL, Probert PK, Berkenbusch K, Nodder SD (2006) Distribution of bathyal meiofauna in the region of the Subtropical Front, Chatham Rise, south-west Pacific. J Exp Mar Biol Ecol 330:342-355

Heath RA (1985) A review of the physical oceanography of the seas around New Zealand-1982. NZ J Mar Freshw Res 19:79-124

> Hecker B (1990) Variation in megafaunal assemblages on the continental margin south of New England. Deep-Sea Res A 37:37-57

> Heip C, Warwick RM, Carr MR, Herman PMJ, Huys R, Smol N, Van Holsbeke K (1988) Analysis of community attributes of the benthic meiofauna of Frierfjord/Langesundfjord. Mar Ecol Prog Ser 46:171-180

> Helson J, Leslie S, Clement G, Wells R, Wood R (2010) Private rights, public benefits: industry-driven seabed protection. Mar Policy 34:557-566

> Hooper JNA, Kennedy JA, Quinn RJ (2002) Biodiversity 'hotspots', patterns of richness and endemism, and taxonomic affinities of tropical Australian sponges (Porifera). Biodivers Conserv 11:851-885

Howell KL, Billet DSM, Tyler PA (2002) Depth-related distribution and abundance of seastars (Echinodermata: Asteroidea) in the Porcupine Seabight and Porcupine Abyssal Plain, N.E. Atlantic. Deep-Sea Res I 49:1901-1920
Knox MA, Hogg ID, Pilditch CA, Lörz AN, Nodder SD (2012) Abundance and diversity of epibenthic amphipods (Crustacea) from contrasting bathyal habitats. Deep-Sea Res I 62:1-9

Labrune C, Gremare A, Amouroux JM, Sarda R, Gil J, Taboada S (2006) Diversity of polychaete fauna in the Gulf of Lions (NW Mediterranean). Vie Milieu 56:315-326

Lambshead PJD, Boucher G (2003) Marine nematode deepsea biodiversity: hyperdiverse or hype? J Biogeogr 30: 475-485

Lambshead PJD, Elce BJ, Thistle D, Eckman JE, Barnett PRO (1994) A comparison of the biodiversity of deep-sea marine nematodes from three stations in the Rockall Trough, Northeast Atlantic, and one station in the San Diego Trough, Northeast Pacific. Biodivers Lett 2:95-107

Leduc D, Probert PK, Nodder SD (2010) Influence of mesh size and core penetration on estimates of deep-sea nematode abundance, biomass, and diversity. Deep-Sea Res I 57:1354-1362

- Leduc D, Rowden AA, Bowden DA, Probert PK, Pilditch CA, Nodder SD (2012a) Unimodal relationship between biomass and species richness of deep-sea nematodes: implications for the link between productivity and diversity. Mar Ecol Prog Ser 454:53-64

Leduc D, Rowden AA, Probert PK, Pilditch CA and others (2012b) Further evidence for the effect of particle-size diversity on deep-sea benthic biodiversity. Deep-Sea Res I 63:164-169

Legendre P (1993) Spatial autocorrelation: trouble or new paradigm? Ecology 74:1659-1673

Legendre P, Anderson MJ (1999) Distance-based redundancy analysis: testing multispecies hypotheses responses in multifactorial ecological experiments. Ecol Monogr 69: $1-24$

> Legendre P, Troussellier M (1988) Aquatic heterotrophic bacteria: modeling in the presence of spatial autocorrelation. Limnol Oceanogr 33:1055-1067

> Levin LA, Gage JD, Martin C, Lamont PA (2000) Macrobenthic community structure within and beneath the oxygen minimum zone, NW Arabian Sea. Deep-Sea Res II 47: $189-226$

> Lörz AN (2010) Biodiversity of an unknown New Zealand habitat: bathyal invertebrate assemblages in the benthic boundary layer. Mar Biodivers 41:299-312

> McKnight DG, Probert PK (1997) Epibenthic communities on the Chatham Rise, New Zealand. NZ J Mar Freshw Res 31:505-513

> Merckx B, Goethals P, Steyaert M, Vanreusel A (2009) Predictability of marine nematode biodiversity. Ecol Model 220:1449-1458

Miljutin DM, Gad G, Miljutina MM, Mokievsky VO, Fonseca-Genevois V, Esteves AM (2010) The state of knowledge on deep-sea nematode taxonomy: How many valid species are known down there? Mar Biodivers 40: 143-159

> Murphy RJ, Pinkerton MH, Richardson KM, BradfordGrieve JM (2001) Phytoplankton distributions around New Zealand derived from SeaWiFS remote-sensed ocean colour data. NZ J Mar Freshw Res 35:343-362

> Muthumbi AW, Soetaert K, Vincx M (2011) Taxon-related diversity patterns from the continental shelf to the slope: a case study on nematodes from the Western Indian Ocean. Mar Ecol 32:453-467

Nodder SD, Pilditch CA, Probert PK, Hall JA (2003) Variability in benthic biomass and activity beneath the Sub- 
tropical Front, Chatham Rise, SW Pacific Ocean. DeepSea Res I 50:959-985

Nodder SD, Duineveld GCA, Pilditch CA, Sutton PJ and others (2007) Focusing of phytodetritus deposition beneath a deep-ocean front, Chatham Rise, New Zealand. Limnol Oceanogr 52:299-314

Nodder SD, Bowden DA, Pallentin A, Mackay K (2012) Seafloor habitats and benthos of a continental ridge: Chatham Rise, New Zealand. In: Harris PT, Baker EK (eds) Seafloor geomorphology as benthic habitat: Geo$\mathrm{HAB}$ atlas of geomorphic features and benthic habitats. Elsevier, Amsterdam, p 763-776

Probert PK, Grove SL, McKnight DG, Read G (1996) Polychaete distribution on the Chatham Rise, Southwest Pacific. Int Rev Gesamten Hydrobiol 81:577-588

Probert PK, Glasby CJ, Grove SL, Paavo BL (2009) Bathyal polychaete assemblages in the region of the Subtropical Front, Chatham Rise, New Zealand. NZ J Mar Freshw Res 43:1121-1135

Proches S, Warren M, McGeogh MA, Marshall DJ (2010) Spatial scaling and transition in pneumatophore arthropod communities. Ecography 33:128-136

Quinn PQ, Keough MJ (2009) Experimental design and data analysis for biologists, 1st edn. Cambridge University Press, Cambridge

Raes M, Vanreusel A (2006) Microhabitat type determines the composition of nematode communities associated with sediment-clogged cold-water coral framework in the Porcupine Seabight (NE Atlantic). Deep-Sea Res I 53: 1880-1894

Rex MA, Etter RJ (2010) Deep-sea biodiversity. Harvard University Press, Cambridge, MA

Ricklefs RE (2008) Disintegration of the ecological community. Am Nat 172:741-750

Rosenzweig ML (1995) Species diversity in space and time, 1st edn. Cambridge University Press, Cambridge

Soetaert K, Heip C (1990) Sample-size dependence of diversity indices and the determination of sufficient sample

Editorial responsibility: Lisandro Benedetti-Cecchi, Pisa, Italy size in a high-diversity deep-sea environment. Mar Ecol Prog Ser 59:305-307

Soetaert K, Heip C (1995) Nematode assemblages of deepsea and shelf break sites in the North Atlantic and Mediterranean Sea. Mar Ecol Prog Ser 125:171-183

Somerfield PJ, Clarke KR (1995) Taxonomic levels, in marine community studies, revisited. Mar Ecol Prog Ser 127:113-119

Somerfield P, Warwick RM (1996) Meiofauna in marine pollution monitoring programmes: a laboratory manual. Ministry of Agriculture, Fisheries, and Food, Lowestoft

> Thrush SF, Hewitt JE, Dayton PK, Coco G and others (2009) Forecasting the limits of resilience: integrating empirical research with theory. Proc Biol Sci 276:3209-3217

> Thrush SF, Hewitt JE, Dayton PK, Coco G and others (2010) $\beta$-diversity and species accumulation in Antarctic coastal benthos: influence of habitat, distance and productivity on ecological connectivity. PLoS ONE 5:e11899

> Uddstrom MJ, Oien NA (1999) On the use of high-resolution satellite data to describe the spatial and temporal variability of sea surface temperatures in the New Zealand region. J Geophys Res 104:20729-20751

> Vanaverbeke J, Merckx B, Degraer S, Vincx M (2011) Sediment-related distribution patterns of nematodes and macrofauna: two sides of the benthic coin? Mar Environ Res 71:31-40

> Vanreusel A, Fonseca G, Danovaro R, da Silva MC and others (2010) The contribution of deep-sea macrohabitat heterogeneity to global nematode diversity. Mar Ecol 31:6-20

Vincx M, Furstenberg J (1988) Three new Xyalidae species (Nematoda) from South Africa, with a redefinition of the genus Xyala Cobb, 1920. Cah Biol Mar 29:497-512

Warwick RM, Platt HM, Somerfield PJ (1998) Free-living marine nematodes. Part III. Monhysterids. Synopses of the British fauna (new series), 53, 1st edn. Cambridge University Press, Cambridge

> Zeppilli D, Mea D, Corinaldesi C, Danovaro R (2011) Mud volcanoes in the Mediterranean Sea are hotspots of exclusive meiobenthic species. Prog Oceanogr 91:260-272

Submitted: November 1, 2011; Accepted: February 23, 2012

Proofs received from author(s): April 3, 2012 